\title{
Language Attrition: An Experimental Qualitative Study on English - Spanish Adult Bilinguals
}


Interest in bilingualism and the effects it has on cognitive development has been subject to immense study and investigation. A relatively new concept associated with bilingualism is attrition. Only in the past 30 years has the study of language attrition become a sub-field of linguistics. It began with a conference in 1980 at the University of Pennsylvania, titled Loss of Language Skills (Lambert \& Freed, 1982). Before the aforementioned conference, language loss was considered to be related to medical illnesses such as language disorders caused by traumas to the head, strokes or tumours. However, according to linguists Schmid and Keijer (2009:2) adult speakers who move to a different linguistic environment tend to experience a change in their first language (L1) proficiency. This research article will focus on bilingual foreign language learners (FLL) who have acquired a second language (L2), in this case Spanish, at a later stage in life. The main objective is to take the influence the second language (L2) has had on the first language (L1) into account. In order to do this, a qualitative study will be carried out on five English - Spanish bilinguals. It will focus mainly on whether each individual involved in the study has encountered some degree of language interference or language loss. Results will be later shown and discussed.

Keywords: Attrition, bilingualism, acquisition, language interference, language decay, language loss.

\section{Introduction}

In the Oxford Advanced Learner's English Dictionary, attrition is defined as: "gradually making something weaker and destroying it, especially the strength or confidence of an enemy by repeatedly attacking it", but what can this have to do with regards to language? The term "First Language Attrition" (FLA) makes reference to a reduction in language proficiency of the native language among native speakers; both Schmid and Keijer explain language attrition in the following way:

Adult speakers who move to a different linguistic environment often experience a change in their first language (L1) proficiency. The language appears to become less easily accessible and word-finding difficulties, interferences from the second language (L2) and lexical and grammatical 'errors' may begin to occur (e.g. Schmid, forthc.). This development is referred to as L1 attrition. (Schmid \& Keijer, 2009: 2).

When people migrate to other countries they are faced with a considerable number of obstacles. One of the main obstacles that must be overcome when moving to a foreign country, where a foreign language exists, is the learning of that language. The research that has been carried out so far on attrition has been done in such a way that 
there are multiple opinions on, first of all explaining exactly what attrition is, and second of all how and why it occurs. Each author has his or her own opinion and methods in order to investigate and understand L1 attrition. Seliger and Vago (1991) establish that first language attrition examines linguistic aspects of the attrition or loss of first language abilities in bilinguals (....) whereas Schmid et al., (2004) state that language attrition research should focus not so much on what appears to be lost in the data under observation, that is, on the apparent 'errors' which are made, but on what is retained. Hence, this paper will focus more so on attrition with regards to language loss. A basic study will be carried out on five English - Spanish bilinguals in order to demonstrate whether or not they have noticed some kind of language attrition (loss) in their L1 language.

Following Schmid and Köpkes (2007) previous studies, the variables that will be taken into consideration in the present research will be i). lexicon/semantics, ii) grammar, iii) phonology/phonetics, and iv) pragmatics).

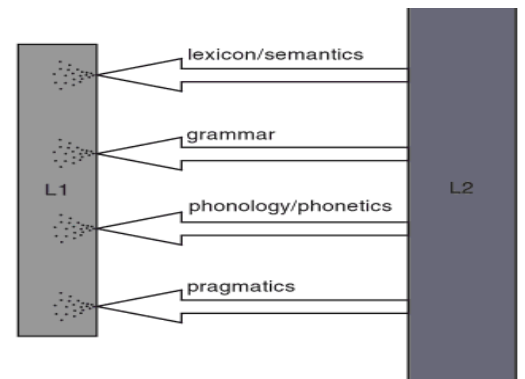

Figure 1. Influence on L1 in L1 attrition (from Schmid \& Köpke 2007:2)

\section{Objectives}

The main objectives of this research article are as follows:

1. To conduct an investigation into what language attrition is.

2. To try to obtain specific results as to whether or not language attrition actually occurred with any one of the participants involved in the experiment.

3. To try and discover to what extent language attrition was present in the different participants and how this influenced their L1.

\section{Variables to taken into account}

Although the aforementioned variables have been briefly introduced by the above authors (Schmid and Köpke, 2007), it is necessary to go into more detail in order to explain their exact meaning and relevance. This will be done as follows by providing different explanations given by various authors. 


\title{
4.1 The lexicon and semantics
}

The lexicon could be described as all the words and phrases that can be used in a particular language by a given person. It is basically what provides any individual with the words he or she may need in order to express themselves. Concerning the lexicon, Pavelenko (2009:209) considers that "although attrition effects can be witnessed across the full range of an individual's linguistic knowledge and use, the lexicon is an area of predominant interest for investigations of $L 2$ influence on $L 1$ ". The reason for this being that the lexicon is a much larger system than other areas of language knowledge. In other words, there are far more words than there are phonetic or morphological items in any given language (Pavelenko, 2009). Semantics on the other hand could be defined as the study of the meanings of words and phrases; therefore it is important to note that although the lexicon and semantics are related to one another, they are not exactly the same.

\subsection{Grammar}

With regards to attrition in grammar and according to Schmid:

\begin{abstract}
Language attrition describes the loss of, or changes to, grammatical and other features of a language as a result of declining use by speakers who have changed their linguistic environment and language habits. In such a situation there may, for example, be simplification in the tense system or in certain properties of subordinate clauses; some vocabulary items might fall into disuse and phonetic features may be restructured. (Schmid, 2011: front cover).
\end{abstract}

Schmid (2011) explains that the above changes can be affected by a number of factors such as, the speaker's environment, the way in which they process and identify the language and finally the learner's attitude towards the new language.

\subsection{Phonology/phonetics}

Phonology could be described as the study of the different systems and patterns of sounds in any given language, and phonetics could be described as the branch of linguistics that studies the characteristics of human sound making, especially those sounds used in speech. Both phonology and phonetics form an important part of language attrition. According to Pavlenko, when attrition occurs "the L2 user would no longer be perceived as a native speaker of his or her L1 when interacting with monolingual speakers of the L1" (Pavelenko, 2004:54) She also speaks of anecdotal evidence that suggests that language attrition with regards to phonology is quite common. One of the examples she gives is taken from a study carried out by a fellow author called Latoma in 1998 and is the case of an American learner of Finnish, in Finland, who after studying Finnish for five years returned to the States and was asked on numerous occasions by different American people where exactly he was from (Pavelenko, 2004). 
L1 Attrition with regards to pragmatics "would involve a loss of pragmatic competence, that is, the inability to interpret particular illocutionary intentions" (Pavlenko, 2004:54). The word illocutionary in the above quote makes reference to an action performed by speaking or writing, for example ordering, warning or promising. This means that a person who has difficulty remembering certain protocols with regards to both writing and speaking in their L1 language has undergone some level of attrition. Pavelenko describes another anecdote about another fellow author known as Canagarajah, whose native origin was Sri Lanka. When Canagaraja returned to Sri Lanka after studying in America for some time he attempted to write articles in the local vernacular Tamil, which was his native language. He structured his papers following the American style of essay writing by using a thesis and an outline of his arguments. This upset and annoyed his colleagues and surprisingly some of his students told him that "the introductory paragraph had sounded a bit too pompous and over-confident" (Canagarajah, 2001:31). The reason for this was because in Sri Lanka the writing style is different. An author normally opens the paper, first of all by stating his or her own limitations on the subject, and then he or she generally gives praise for the audience's knowledge. Obviously Canagarajah neglected to do so, not because it was not of importance to him, but because he had simply forgotten the Tamil style of writing.

The above variables will be used within this research to investigate as to whether the participants have undergone some level of language attrition throughout their learning and acquisition process and whether this attrition causes some kind of interference in their daily lives.

\section{Method and Materials}

In order to carry out this study a very basic questionnaire was formed. It contained a total of 16 short questions related to the above variables and also asked for some background information on each participant. Out of the sixteen questions four of them were based on background information and 12 other questions referred to the previously mentioned variables ( 3 for each variable). They were relatively short and to the point so as not to confuse either the participant or the assessor. The questionnaire that was used can be seen in appendix 1 and a brief description of both the participants and the answers they gave can be clearly seen in table 1 below. The participants involved in this questionnaire were four females and one male. There is no particular reason for this except that the task of finding English - Spanish bilinguals who had the specific characteristics needed was more difficult than had been previously anticipated.

Before starting this experiment it was first of all necessary to find at least 5 English-Spanish bilinguals who had acquired Spanish at a later 
stage in life (from the ages of 20-30). Once this had been accomplished it was then necessary to structure the questionnaire, first of all, so that it was coherent with the aforementioned variables and second of all, so as to obtain the most specific feedback possible in order to achieve the most valid results possible. All five participants were sent the questionnaire by email due to the fact that most of them did not have very flexible timetables. Each one had a time span of up to three days to answer, first of all so that they would not spend too much time thinking about their answers and second of all because the answers needed to be processed and evaluated adequately within a limited period of time.

Once the results had been received a table was drawn up in order to evaluate each participant's answers individually. The number one was used for questions that were answered with a "yes", number two was used for questions that were answered with a "no», and number three was used for questions that were answered «both». For questions that required the answer "yes" number one was used and for questions that were answered «no» number two was used.

Once this was done a colour code was used in order to see which answers coincided, which were similar, which were slightly different and which were mixed. The following table reveals a portrayal of the aforementioned system of evaluation.

Table 1. Evaluation system

\begin{tabular}{|c|c|c|c|c|c|c|}
\hline Question & Anita & Paul & Laurie & Kaye & Justine & Colour \\
\hline Other languages & 1 & 1 & 1 & 1 & 1 & \\
\hline Most dominant language & 1 & 2 & 2 & 1 & 3 & \\
\hline Continuous contact English & 2 & 1 & 1 & 1 & 1 & \\
\hline Most comfortable speaking & 1 & 2 & 2 & 3 & 2 & \\
\hline Introduces Spanish words & 1 & 1 & 1 & 1 & 1 & \\
\hline Uses words like mentalise & 1 & 1 & 1 & 1 & 1 & \\
\hline Simplified speaking & 1 & 1 & 1 & 1 & 2 & \\
\hline Word searching & 1 & 1 & 1 & 1 & 1 & \\
\hline Grammatical structure & 2 & 1 & 1 & 2 & 2 & \\
\hline Others understanding & 2 & 2 & 2 & 2 & 2 & \\
\hline Change in pronunciation & 2 & 1 & 1 & 2 & 1 & \\
\hline Change in accent & 2 & 1 & 2 & 1 & 1 & \\
\hline Pronunciation - forget & 1 & 2 & 1 & 2 & 1 & \\
\hline Difficulties - Expression & 1 & 1 & 1 & 1 & 2 & \\
\hline Speaking slower & 2 & 1 & 2 & 1 & 2 & \\
\hline Translate Spanish to English & 2 & 1 & 2 & 2 & 2 & \\
\hline
\end{tabular}

\begin{tabular}{|l|}
\hline Number Code \\
\hline Yes $=1$ \\
\hline No $=2$ \\
\hline Both $=3$ \\
\hline
\end{tabular}

\begin{tabular}{|l|}
\hline Colour Code \\
\hline Coinciding answers = Purple \\
\hline Similar answers = Grey \\
\hline Mixed answers = Pink \\
\hline
\end{tabular}




\section{Participants}

All five participants involved in the task have very diverse situations with regards to both the amount of time living in Spain and their use of the English language; therefore it is necessary to give a brief account of each one.

Anita is British and has been living in Spain for over 38 years. She is married to a Spanish man and has very little contact with her native language since she came to Spain. Paul is American and has been living in Spain for over 30 years. He is married to a Spanish woman and is in constant contact with his native language as he is an English teacher. Both Justine and Laurie are also American. Justine has been living in Spain for over 28 years, speaks 2 other languages and is also in constant contact with her native language. Laurie has been living in Spain for over 20 years. She is married to a Spanish man and uses English on a daily basis; both in the work place and with her children at home. And finally Kaye is British, she has been living in Spain for over 20 years, she is married to a Spanish man and she also is in continuous contact with the English language as she too teaches English.

\section{Results}

The following graph shows the individual results obtained from each of the participants.

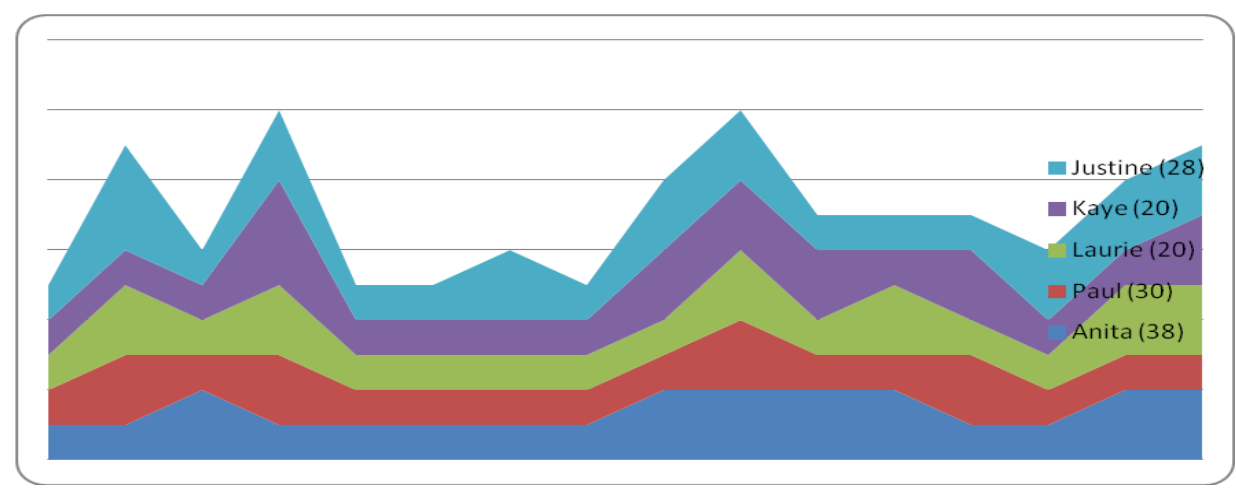

Figure 2. Results of each individual participant's questionnaire

Although the results shown in the above illustration seem to be quite homogenous, there were some surprising differences. They will be discussed in more detail as follows.

All of the participants, except one, were in continuous contact with their native language and used it on a daily basis. The only member who was not in continuous contact with her native language showed that surprisingly enough she did not notice a change in her pronunciation or accent, whereas other members who were in continuous contact with their native language did. 
Although the majority of the participants admitted that English was the most dominant language in their daily lives, and that they felt most comfortable speaking in their native language, they found that they had noticed a tendency to use Spanish grammatical structures when speaking in English.

When asked about whether they had noticed a change in their accent, a change in their pronunciation, and whether or not they sometimes faced difficulties with regards to pronouncing new words in English the majority of the participants agreed.

Finally, all of the participants coincided with their answers in five of the sixteen questions and they are as follows. They all spoke another language apart from English and Spanish, they all found that they introduced Spanish words in the middle of English sentences without actually wanting to, all of them used calquing, that is, they used Spanish words in English, thinking that they had the same meaning (e.g. mentalise), they all found difficulties when having to express themselves to native speakers as they found they could not recover specific English vocabulary, and lastly, none of them found that they had lost their English so much that native English speakers could not understand them correctly.

\section{Conclusion}

From the previously shown results the following conclusions can be made:

- First of all, despite the fact that most of the participants interact a great deal in their native language significant signs of language attrition in general were detected.

- With regards to phonetics, it has been clearly demonstrated that in almost all of the participants the L2 has had an appreciable effect on both their accent and their pronunciation.

- English grammatical structures were also modified in most cases, sometimes even without the person realising language attrition was taking place.

- What is more important modifications with regards to pragmatics were made. The majority of the participants found that they were speaking slower in their native tongue and some even found themselves, on occasion, translating in their minds from the $L 2$ into the $L 1$.

The above results prove that the majority of $\mathrm{L} 2$ learners, who have acquired a second language in a foreign country as an adult, can and should expect to undergo some degree of language attrition throughout their lives.

It is of great importance to mention here that although each participant has acquired and experienced language learning in completely 
different situations, it can be appreciated from this specific study that all of them have undergone some level of language attrition. It can be clearly seen that their $L 2$ language has had a reasonable influence on their L1 language in all of the previously mentioned variables. Notwithstanding, it is necessary to state that there are quite a number of limitations within this research article. The study that was carried was not a specific study especially elaborated by a qualified professional for language attrition, nor is it a study that is entirely trustworthy due time limitations and sufficient research. Finally, the fact that the questionnaire was sent by email suggests that first of all the questions may not have been interpreted the way the assessor wished them to be, and second of all, the answers that were given may not have been apprehended adequately.

Despite these restrictions the findings of the study reported here have contributed to the principle aim of this article, which was to basically show what exactly language attrition is, and if it actually manifests itself in foreign language learners. Although the influence of the $L 2$ language on the $L 1$ language is clear from the descriptive statistics alone, it is essential to state that in order to have a greater understanding of how the mind works and why it works the way it does, further and more complex studies would have to be carried out. It is also necessary to mention that all of the above variables can be related to linguistic phenomenon such as lexical retrieval, linguistic distortion, language decay and linguistic interference all of which are complicated concepts and would need to be explained in greater detail.

Finally and to conclude, it is of great significance to convey that although the above results are worthy of attention, some of the results were somewhat different. Further studies that could be carried out with regards to language attrition could be in order to investigate why language attrition affects second language learners the way it does and why some people notice some differences that others clearly do not.

\section{Acknowledgements}

I would like to thank María Noelia Ruiz Madrid, María del Pilar Safont Jordà, and Antonio José Silvestre López from the University Jaume I for their valuable advice. I would also like to thank the participants who made this experimental study possible. 
CANAgARAjaH, S. (2001: 23-37). "The Fortunate Traveller: Shuttling Between Communities and Literacies by Economy Class». In D. Belcher and U. Connor (Eds.), Reflections on Multiliterate Lives. Clevedon: Mulitlingual Matters.

KÖPKE, B. et al. (eds.) (2007). Language Attrition: Theoretical Perspectives, John Benjamins Publishing Company,Amsterdam.

LAMBERT, R. D. and B. F. Freed (1982). The Loss of Language Skills, Rowley, MA: Newbury House.

Pavelenko, A. (2004 47-59). «First Language Attrition: Interdiciplinary Perspectives on Methodogical Issue». In M. S. Schmid, B. Köpke, M. Keijzer, and L. Weilemar, (Eds). L2 Influence and L1 Attrition in Adult Bilingualism: John Benjamins Publishing Company. Amsterdam

Pavelenko, A. (2009). The Bilingual Mental Lexicon: Interdiscipilinary Approaches, The Cromwell Press Ltd, Great Britain.

SCHMID, M. S. (2011). Language Attrition, Cambridge University Press, Cambridge.

SCHMID, M. S. et al. (eds). (2004). First Language Attrition: Interdisciplinary Perspectives on Methodological Issues. John Benjamins Publishing Company, Amsterdam.

SCHMID, M.S. and M. KEIJZER (2009). «First Language Attrition and Reversion among Older Migrants». International Journal of the Sociology of Language.

Seliger, H.W and R.M Vago. (1991). First Language Attrition, Cambridge University Press, Cambridge. 